\title{
COMPARING THE EFFECT OF HEAT TREATMENT AND PLASMA-NITRIDINGON CORROSION RESISTANCE OF Ni-B-CNT ELECTROLESS COATING WITH DIFFERENT CNT CONCENTRATION ON AISI 4340 STEEL
}

\author{
ALAA MOHAMMED HUSSEIN WAI ${ }^{1}$, ABDUAL RAHEEM K. ABID ALI ${ }^{2} \&$ FARZAD MAHOUB ${ }^{3}$ \\ ${ }^{I}$ Al-Mustaqbal University College, Iraq \\ ${ }^{2}$ University of Babylon / Material Engineering, Iraq \\ ${ }^{3}$ Amirkabir University of Technology, Iran
}

\begin{abstract}
The aims of the work to study the resistance of corrosion and the hardness of plasma-nitrating and heat treatment of coatings with electroless $N$ i-B-CNT. Various concentration of CNT range, $(0,0.35$ and 0.7$) g / L$ in Ni-B-CNT composite was deposit on 4340 steel in electroless immersion. Following the procedure of plating, every samples were plasma-nitrating in atmosphere consist of $50 \% \mathrm{~N}_{2}-50 \% \mathrm{H}_{2}$, about $\left(400^{\circ} \mathrm{C}\right)$, at $(2.5 \mathrm{~h})$ were compared with those of annealed one. The electrodes Ni-B-CNT coatings were prepared by using nickel chloride as source for nickel, borohydride act as reducing agent and used (MWCNT). Results of micro hardness was show that the higher hardness of (1250HV) was achieved for Ni-B-0.35g/L CNT plasmanitrating formula whereas the greatest hardness of $(1010 \mathrm{HV})$ was become for sample of Ni-B-0.35g/L CNT heat treated. Resistance of corrosion of Ni-B-CNT composite coating are better, and they become much better with the increase of the CNT concentration. Increase too much CNT deposited on the substrate, leading to a high region of CNT and agglomeration that occur is very unfavorable to coating, lead resistance of the corrosion of the composite coating becomes worse. Also, compared between heat treatment and plasma-nitride, results of that resistance of the corrosion with plasma-nitriding is better KEYWORDS: Electroless Ni-B-CNT Coating, Plasma -Nitriding, Heat Treatment Micro Hardness \& Resistance of Corrosion
\end{abstract}

Received: Jun 06, 2019; Accepted: Jun 26, 2019; Published: Sep 05, 2019; Paper Id.: IJMPERDOCT201917

\section{INTRODUCTION}

In recent times, plating technique by using of aqueous solutions (electroplating plus electroless plating) obtain a great consideration due to the aims like easy of the coating technique, large rate of deposition, low cost, preparation of uniform layer of coating plus promising final properties like good wear resistance, high hardness, and a good anticorrosion properties [1-4].

Electroless nickel coating technique is more famous as compare with aqueous solution metal deposition technique, also has experience notable modifications so its discovery by Branner and Riddell in 1946. The technique has some distinct feature like uniform high hardness, thickness, abrasion resistance and good wear, good solder ability, excellent resistance of corrosion, amorphous and/or microcrystalline deposit, high reflectivity, low coefficient of friction, low resistivity and good magnetic properties. Their work led to the development of the 'kanigen' process (catalytic nickel generation) by the General American Transportation Corp (G.A.T.C.) which launched a pilot line in $1955[5]$.

The first borohydride reduced bath was proposed in 1954 and the technology was developed in 1957-1958, less than 20 years after the first synthesis of sodium borohydride [6]. 
Applications of electroless coatings are use in different areas such as powder metallurgy, MEMS, electromagnetic interference (EMI), heat exchangers, reactor membranes, and reduction of bacterial adhesion. Electroless coating technique have advantage of thickness uniformity when compare with the electrode position technique [7-10].

The apparent advantage of boron and promising benefit of coating electroless technique, enhance properties of surface with depositing Ni-B coating during coating electroless technique be concerning as a reasonable choice. Following its maturity, repeatability and scalability in 1989, Ni-B coating electroless technique was adopt as a mass production technique. Technique of Ni-B the electroless coating is obtaining remarkable attention to enhance the properties of surface of a large types of substrates [11-12].

$\mathrm{Ni}-\mathrm{B}$ electroless coating formation a uniform platings that contain significant amount of nickel boride that cause of substantial enhancement in wear plus properties of abrasion [13-15].

Different type of base metal materials can be used involve stainless steel, carbon steel, aluminium plus aluminium alloys, iron, glasses, plastics. The advantage of Ni-B electroless coating involve a good hardness (higher than steel of tool), extreme resistance of wear (superior as compared by hard chromium coatings) plus promising features of corrosion resistance (Ni-P coating). In addition to these advantages, uniform thickness, low cost, good lubricity, high wear resistance, corrosion resistance and promising ductility, marvelous solder ability, large properties of electrical, large bonding, very good conductivity[16].

Commonly, technique of Ni-B electroless coating is thought to be better when compared with Ni-P coating also is more attractive in many industries $[17,18]$.

Little of investigators have in study of heat treatment of $\mathrm{Ni}-\mathrm{B}$ in a vacuum with plasma nitriding [19]. Improved of mechanical properties, resistance of wear and resistance of corrosion, and coatings of nano composite have great deal of attention. Nano composite coating has another appropriate identified solid lubricants like $\mathrm{MoS}_{2}$ [20], PTFE [21] and CNT [22] in which can act to decrement in the coefficient of friction with improve the resistance of wear on the surface. Because of a great tensile strength of carbon nano tubes with elastic modulus [23], make it widely used in ceramic composites and metallic composites such Cu-CNT [24], ZrO2-CNT [25] and Ni-P-CNT [26].

Plasma-nitriding can be executed with equal temperature ranged for conventional heat treating of Ni-B-CNT coatings and a good process for enhancing the surface properties of different engineering materials, It can be used for posttreatment of electroless Ni-B-CNT coatings [27].

The aim of this studying is explain effects behaviour of electroless Ni-B-CNT coating with various concentrations of CNT, Plasma-nitriding and heat treatment coating on some mechanical properties (micro hardness and roughness), resistance of corrosion and microstructure of 4340 alloy.

\section{EXPERIMENTAL}

\section{Preparation of Substrate}

The substrate metal used in this work was 4340 steel, specimens $(20 \mathrm{~mm}$ diameter $\times 10 \mathrm{~mm}$ height) were used as the substrates. The chemical analysis for this alloy and Details composition (weight\%) is shown in table

To enhance the mechanical properties like toughness and hardness, the base metal were undergo to heat treatment (hardening and tempering), heating to $850^{\circ} \mathrm{C}$ for one hour then in oil quenching. following, the substrate was tempered at 
in temperature $400^{\circ} \mathrm{C}$ for one hour, then cooling in air to room temperature .All specimens were grinded and polished as ASTM by emery paper (tungsten oxide paper) No. (180-2000), Then samples were wash with distilled water and ethanol, and dried by electrical dryer. A polishing was conducted by diamond paste, Specimens were immersion in acetone for 30 min , Before coating ,Specimens were immersion in solution include materials $(60 \mathrm{~g} / \mathrm{L} \mathrm{NaOH}, 38 \mathrm{~g} / \mathrm{L} \mathrm{NaCO}$ and $30 \mathrm{~g} / \mathrm{L}$ $\mathrm{NaPbo}_{4}$ for one minutes period at $70^{\circ} \mathrm{C}$ temperature with moving the electrolyte using magnetic stirring by supply power (5 volt)to remove oil and dust from the surface of metals, follow that the specimens were washed by distilled water, the specimens dry by using an electrical dryer and after that ,it directed immersion in coating solution and After that, the specimens dry with using an electrical dryer, and the samples were placed in desiccators which containing particles of silica gel to absorb wetness to keep the samples from corrosion.

Table 1: Chemical Compositions of 4340 Steel

\begin{tabular}{|c|c|c|c|c|c|c|c|c|c|}
\hline Element & $\mathbf{C}$ & $\mathbf{S i}$ & $\mathbf{S}$ & $\mathbf{M n}$ & $\mathbf{P}$ & $\mathbf{C r}$ & $\mathbf{N i}$ & $\mathbf{M o}$ & $\mathbf{F e}$ \\
\hline AISI & $0.3-0.45$ & $0.2-0.4$ & $\begin{array}{c}\text { Max } \\
0.04\end{array}$ & $0.5-0.8$ & Max 0.04 & $0.6-0.9$ & $1.25-1.75$ & $0.15-0.25$ & Bal. \\
\hline W\% & 0.36 & 0.29 & 0.01 & 0.67 & 0.01 & 0.81 & 1.3 & 0.15 & Bal. \\
\hline
\end{tabular}

\section{CNT Ball-Milling}

MWCNT with purity more than 95\%, 10-30 $\mu \mathrm{m}$ with length, 5-10nm in inside diameter and 20-30 nm with outer diameter, are purchased from US Research Nano materials, Inc. For to improve the dispersion of CNT in bath of electroless coating, as-received CNT were ball-milled for $3 \mathrm{~h}$ using by planetary ball-mill machine with balls of steel with various diameters have been used for mix CNT in cylindrical stainless steel jar, rotating speed and then (10 min) fracture Intermitting each $(20 \mathrm{~min})$ of milling to reduce heat build-up. Ethyl alcohol has been used in wet mixing. Figure1shows Field Emission Scanning Electron Microscopy in MIRA3 TESCAN company in Iran, images of as-received and ball milled CNT. The mage show ball milled CNTs are smaller and more straight so to enhance the dispersion of CNTs at electroless bath.

In order to dispersed uniformly carbon nano tubes in a electroless Ni-B coatings, no agglomeration to a given homogenous and stable dispersion through the metallic matrix phase. Should use surfactants SDS (sodium dodecyl sulfate with CNT and together mixed with water by ultrasonic device for $45 \mathrm{~min}$.
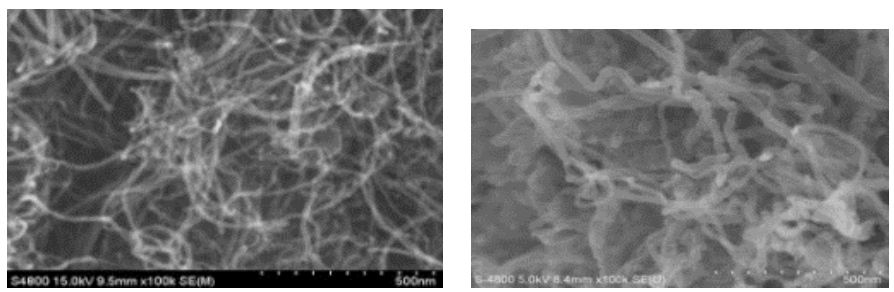

Figure 1: FESEM Images of (A) As-Received CNT and (B) Ball Milled CNT.

\section{Electroless Bath Preparation}

After completion of preparing surfaces for coating, electroless bath were prepared for the process according to concentrations shown in table 2. The coating of Ni-B was deposited on the 4340 steel via electroless coating procedure. $\mathrm{pH}$ value of coating bath was varied between (12-14). The coating electroless of Ni-B perform at $\left(95 \pm 1^{\circ} \mathrm{C}\right)$ for $(60 \mathrm{~min})$. Through of coating ,solution of bath agitate by magnetic stir to avoid localized overheating and reduce the fluctuation of ionic 
concentration. Every $10 \mathrm{~min}$ the specimen was revolved about two opposite directions to get constant plating thickness. As the coating procedure of Ni-B-CNT deposition with various concentration of CNT $(0.35 \mathrm{~g} / \mathrm{L}, 0.7 \mathrm{~g} / \mathrm{L} \mathrm{CNT})$, firstly CNT were dispersed in ultrasonic bath, then addition of CNT to the Ni-B prepared bath. Figure 2 shows the setup of electroless composite deposition. After the completion of the process of coating, specimens were placed inside a vacuum oven, to dry for 30 minutes, at a temperature $50^{\circ} \mathrm{C}$.

Table 2: Operating Conditions for Electroless Bath

\begin{tabular}{|l|c|}
\hline Bath Composition & g/L \\
\hline Nickel chloride $\left(\mathrm{NiCl}_{2} \cdot 6 \mathrm{H}_{2} \mathrm{O}\right)$ & 24 \\
\hline Sodium borohydride $\left(\mathrm{NaBH}_{4}\right)$ & 0.8 \\
\hline Ethylenediamine $(98 \%)(\mathrm{EDA})$ & $60 \mathrm{ML} / \mathrm{L}$ \\
\hline Lead Nitrate & 0.02 \\
\hline Sodium hydroxide $(\mathrm{NaOH})$ & 90 \\
\hline Sodium Dodecyl Sulfate $(\mathrm{SDS})$ & 2 \\
\hline Carbon nanotube(CNT) & $0,0.35,0.7$ \\
\hline Operating conditions & \\
\hline pH & $(12-14) \mathrm{OR} 13$ \\
\hline Temperature & $95^{\circ} \mathrm{C}$ \\
\hline Time & $1 \mathrm{HR}$ \\
\hline
\end{tabular}

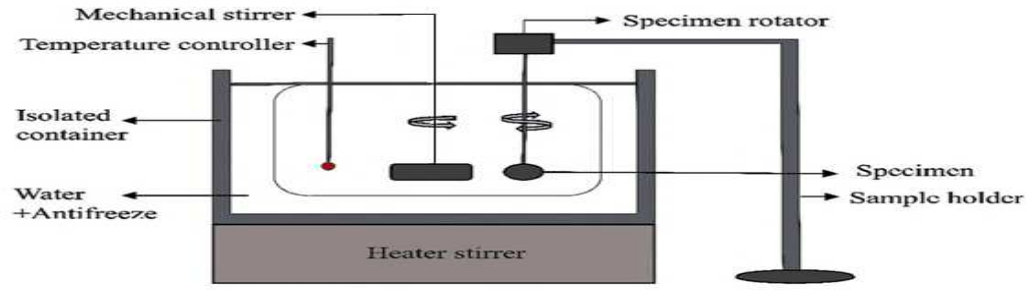

Figure 2: Setup of Experimental for Electroless Deposition.

Plasma Nitriding and Heat Treatment of Coated Samples

Table 3: Operating Conditions of Plasma

Nitriding Treatment

\begin{tabular}{|l|l|}
\hline \multicolumn{1}{|c|}{$\begin{array}{c}\text { Pulse Dc Plasma } \\
\text { Nitriding (PPN) }\end{array}$} & \multicolumn{1}{c|}{ Conditions } \\
\hline $400^{\circ} \mathrm{C}$ & Temperature $\left({ }^{\circ} \mathrm{C}\right)$ \\
\hline $10^{-3}$ torr & Pressure \\
\hline $400-500 \mathrm{~V}$ & discharge voltage \\
\hline $8.9 \mathrm{kHz}$ & Frequency \\
\hline $70 \%$ & Duty cycle \\
\hline $2-3$ & Current $(\mathrm{A})$ \\
\hline$\left(50 \% \mathrm{~N}_{2}-50 \% \mathrm{H}_{2}\right)$ & Gas composition \\
\hline 2.5 & Duration $(\mathrm{h})$ \\
\hline
\end{tabular}

After the deposition, every samples (Ni-B,Ni-B-0.35g/L CNT,Ni-B-0.7g/L CNT) degrease used acetone follow that were placed in a $(5 \mathrm{~kW})$ direct current of plasma to increase PECVD (chemical vapor deposition) chamber. Annealing process was conducted in vacuum furnace for electroless coating samples at $400^{\circ} \mathrm{C}$ for 2.5 hour. Working conditions for the plasma-nitrided treatment for electroless bath, was shown at table 3.In the ending of the process, the specimens were gradually cool in the chamber to arrival the room temperature. 


\section{Characterization}

Micro hardness of the coating layers were measured by using (TH-717 Vickers hardness tester), $25 \mathrm{~g}$ load was applied for 15 sec. Three readings were recorded for each specimen coated and one at the substrate. Then, the average value was taken. The test of roughness of surface measurement was carried out for the plated specimens before and after heat treatment and plasma nitriding treatment using a common parameter Ra in $\mu \mathrm{m}$. Test of surface roughness (HER210 Model) was used to calculate Ra with accuracy $0.05 \mu \mathrm{m}$ and the mean of (10) measurements was recorded. The coatings were examined to identification of the crystalline phase. The phase of coating was identified by XRD (X-ray diffraction) EQuinox 3000, operated with (40 kV and $30 \mathrm{~mA})$ was obtained to identify structure of crystal of the specimens before and after heat treatment and treatment of plasma nitriding, by $\mathrm{Cu} \mathrm{Ka}(\mathrm{X}=1.54187 \mathrm{~A})$ energy with scanning range of 20 between $\left(5^{\circ}\right.$ and $\left.118^{\circ}\right)$.Corrosion behavior of the coatings was evaluated by Tafel extrapolation technique. They obtained corrosion parameters that are the potential of corrosion is difference of the voltage between a metal immersed in a given environment and standard reference electrode (Ecorr)., corrosion current density (icorr)., and corrosion rate coatings, in $3.5 \% \mathrm{NaCl}$ solution.

\section{RESULTS AND DISCUSSIONS}

\section{XRD}

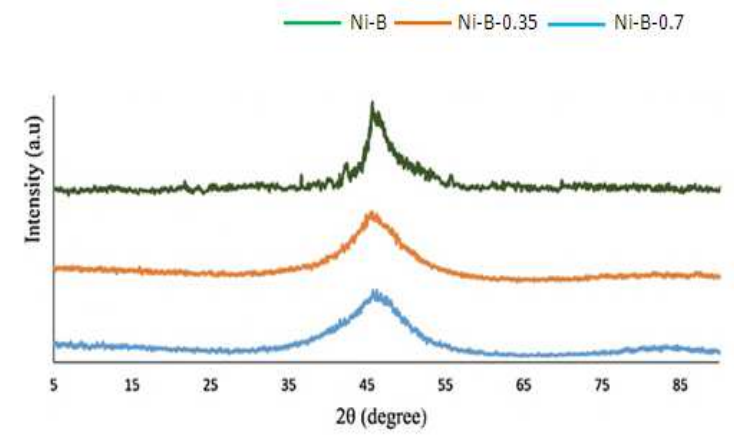

Figure 3: XRD Patterns of as-Plated Ni-B and Ni-B-CNT Samples.

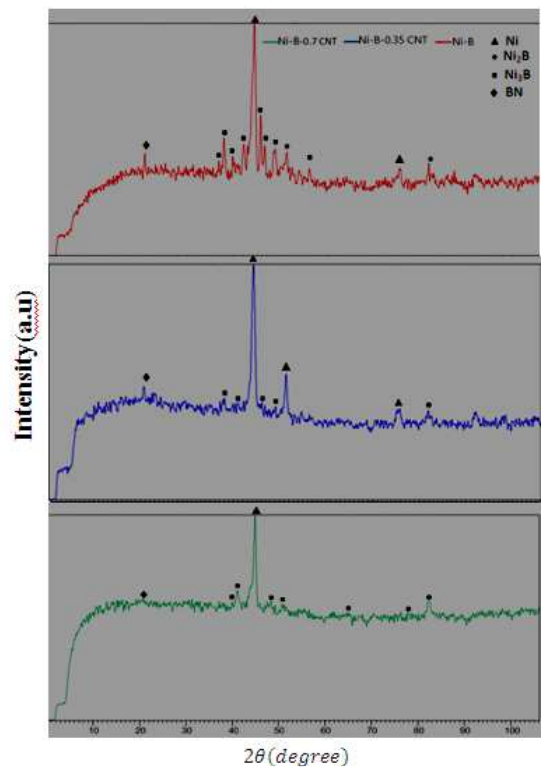

Figure 4: XRD Patterns of Plasma-Nitrided Ni-B and Ni-B-CNT Samples. 
Patterns of XRD of coating Ni-B shows are presented in figure 3. A broad peak XRD pattern of deposited electroless Ni-B coating was shown in Figure 3ain which indicates that an amorphous structure. This result was also have been reported by many papers have stated an amorphous and semi-crystalline microstructure for coating Ni-B. Amorphous element as boron prevent the nucleation phase of nickel [28].

Peak broadening was noted reduce when addition CNT in the electroless bath, and as increase the concentration of CNTs in the electroless bath the peak became sharper, and this can be determined with the effects in Ni-B-CNT samples when $\mathrm{H}+$ ions are librate from carboxylic sets that present about the surface of CNTs while residual (HCOO-) ions work as a reducing agent so decreases the Ni ions. consequently, Ni begin to nucleation on the crystal flaws of CNTs in which worka site of nucleation and the microstructure of coating Ni-B-CNT became more semi-crystalline with increase CNT concentration. The same phenomena can been observed with additionSiC particles [29].

The microstructure of coated specimens was altered from amorphous to crystalline state follow the plasma nitriding treatment in Figure4, because formation of intermetallic compounds Ni2B and Ni3B. They can be appealed the present of the Ni3B phase is product from the decomposition of unbalanced (Ni2B) phase or too can be the product of the irregular distribution of boron by little concentration. In addition to that, constant bombardment of cathodic stage with positively charged ions can be in increase in the temperature of surface of specimens and led for the growth up of the Ni2B and Ni3B phase. The peak that noted at every specimens may be related to microstructure of boron nitride ( $\mathrm{BN})$ [30]. The sputtered boron atoms in plasma atmosphere reacted with active nitrogen and form BN after that deposited on the specimen surface

\section{Surface Morphology}

Figure 5 shows morphology of surface of the coated sample, in which the smooth micro structure of Ni-B sample can be noted in image in Figure 5a and exhibit a cauliflower type microstructure. These type of structure can be benefit in keeping lubricants below conditions of adhesive wear [31, 32].

A larger part of the CNT were found fixed in the matrix through the particle distribution while the lesser art were protruded from the surface of coated; on the other hand, CNTs were present at the surface of specimen containing $0.35 \mathrm{~g} / \mathrm{L}$ CNT in Figure 5b. Furthermore, important change in the microstructure was observed in the specimen containing $0.35 \mathrm{~g} / \mathrm{L}$ of CNT, which seems logical and lead to increase uniformly coated surface, in which CNT have the capability to fill the crevices and gaps because of low concentration of nano tubes. When with increasing the concentration to $0.7 \mathrm{~g} / \mathrm{Lof} \mathrm{CNT}$ the size of the growth of nodules. These result related with the increased concentration of reduce $\mathrm{Ni}$ at the bath of electroless which could lead to the growth to minimize nucleation in Figure 5c. The CNTs aggregation that was be observed result from presence of big particles about Ni-B-0.7g/l CNT specimen owing to the great concentration of them. These led to agglomeration of CNT on the base metal and so consequently big particles on the surface of samples might be shaped related to the nucleation of Ni on agglomeration of CNT. So as to prove the CNT distribution become very clearly, image with larger magnification of specimen is also added in figure $5 \mathrm{~d}$.

Figure (6) FESEM observations of the samples with heat treated show that the coated Ni-B appear semi-bright, while the heat treated of Ni-B coatings are matte in appearance, earlier study was shown that the Ni-Bnodules are almost flat and uniformly dispersed in as-deposited condition. While heat is treated, the nodules grow in size giving rise to a coarse-grained structure [33]. 

of Ni-B-CNT Electroless Coating with Different CNT Concentration on Aisi 4340 Steel

In figure 7 observations of FESEM for the samples of plasma-nitrided showed change the morphology of surface $\mathrm{Ni}-\mathrm{B}$ to cauliflower-like microstructure with very clearly in figure7a. The type of the structure seen may be due to a perfect deposition to defect sites of the surface in begin of the process [31, 34].

Figure $7 \mathrm{~b}$ shown a sample that containing $0.35 \mathrm{~g} / \mathrm{L}$ CNT similar densification was happened In actuality, the growth of crystals were initially nucleated at diverse favored sites has cause $\mathrm{Ni}_{2} \mathrm{~B}, \mathrm{Ni}_{3} \mathrm{~B}$, and $\mathrm{BN}$ particles at coincide by cover the surface of the specimen. In addition to that, re-deposition and sputtering of the atoms may work on the redeposited compounds to fill the spaces through treatment of plasma nitriding. The sample that contain $(0.7 \mathrm{~g} / \mathrm{l} \mathrm{CNT}) \mathrm{had}$ a coarser particles in figure 7c. Follow the plasma nitriding treatment the agglomerated particles noted to be 2 or 3 times larger and this due to a high CNTs concentration which can causes more rate of growth and nucleation of the nano clusters in this sample. On the other hand, no indication of the CNTs in the specimen surface of was noted. This final result related, a fixed ion bombardment through process of plasma nitriding has eliminate the too much CNT from the surface.
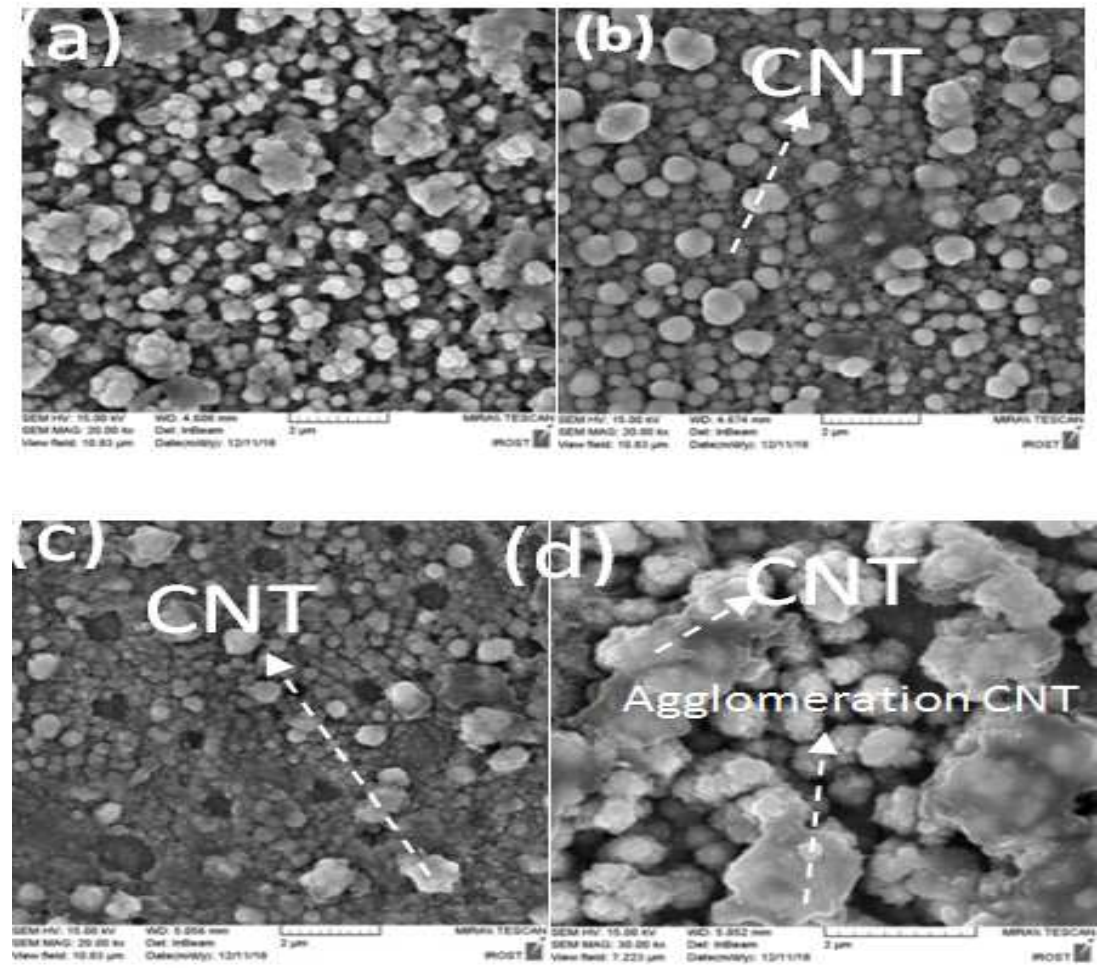

Figure 5: FESEM Images of Electroless Coating(a) Ni-B, (b) Ni-B-0.35g/L CNT, (c) Ni-B$0.7 \mathrm{~g} / \mathrm{L}$ CNT,(d) Higher Magnification ofNi-B-0.7g/L CNT.

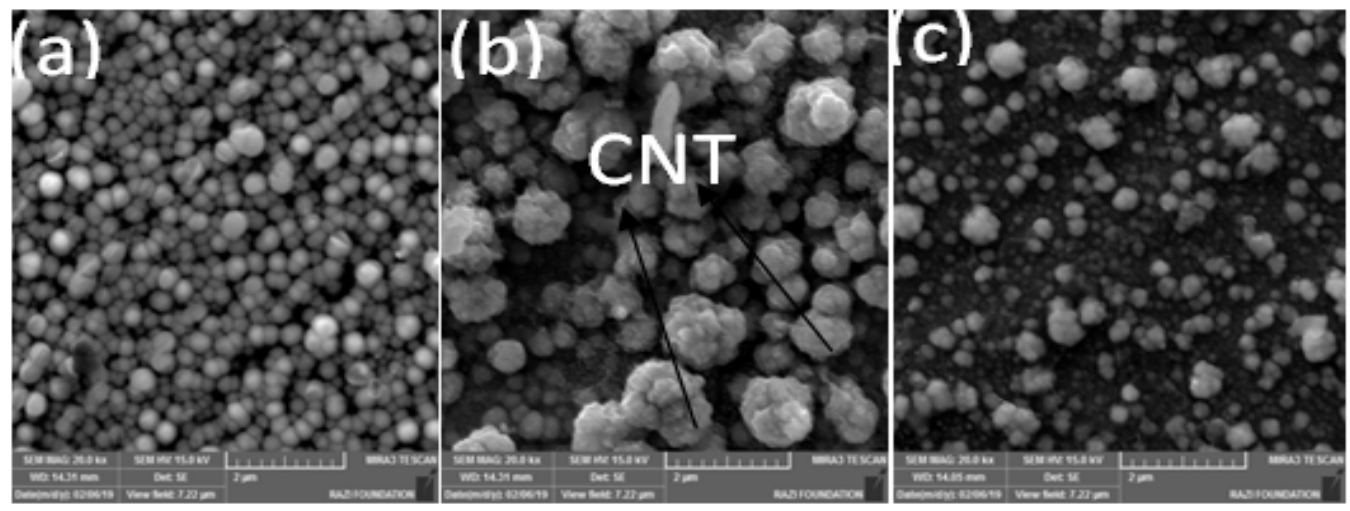

Figure 6: FESEM Images of Plasma Nitriding (A) Ni-B, (B) Ni-B-0.35g/L CNT, (C) Ni-B0.7g/L CNT. 


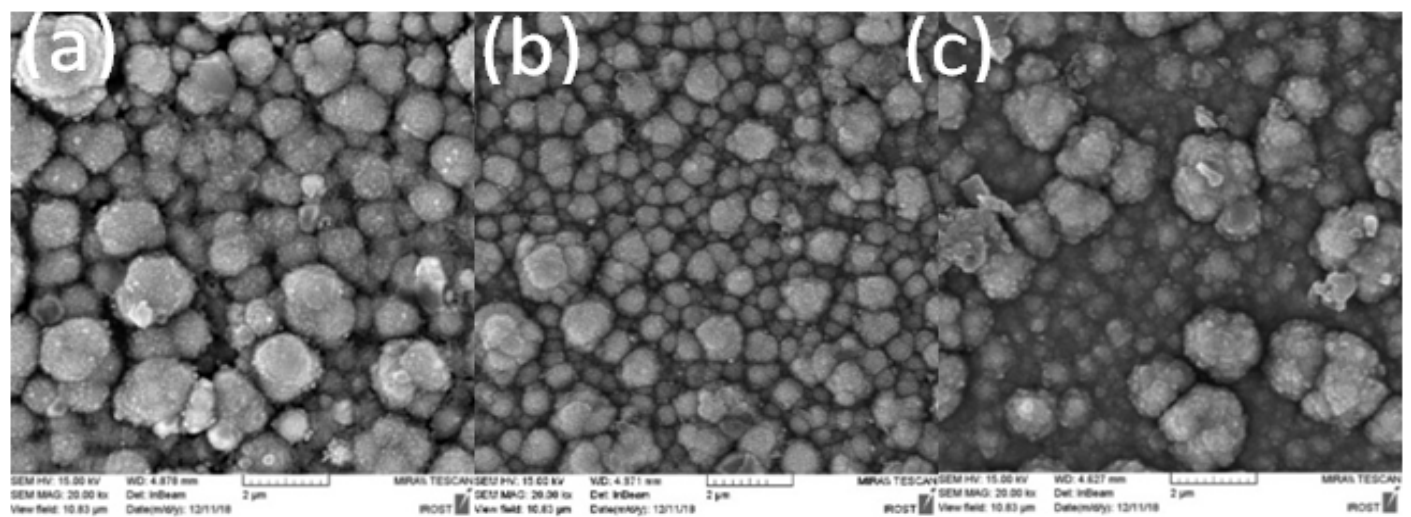

Figure 7: FESEM Images of Plasma-Nitrided(a)Ni-B,(b)Ni-B-0.35g/L CNT,(c)Ni-B-0.7g/L CNT.

\section{Surface Roughness}

Table 4: Result of Specimens Surface Roughness

\begin{tabular}{|l|c|}
\hline \multicolumn{1}{|c|}{ Sample } & $\mathbf{R a}(\boldsymbol{\mu})$ \\
\hline Substrate & 0.3 \\
\hline Ni-B as-a plated & 0.1 \\
\hline Ni-B-0.35g/L CNT as-a plated & 0.17 \\
\hline Ni-B-0.7g/L CNT as-a plated & 0.2 \\
\hline Ni-B as-annealed & 0.26 \\
\hline Ni-B-0.35g/L CNT as-annealed & 0.24 \\
\hline Ni-B-0.7g/L CNT as-annealed & 0.28 \\
\hline Ni-B as-a plasma-nitrided & 0.34 \\
\hline Ni-B-0.35g/L CNT as-a plasma-nitrided & 0.21 \\
\hline Ni-B-0.7g/L CNT as-a plasma-nitrided & 0.4 \\
\hline
\end{tabular}

Roughness of the substrate data was illustrated in table 4, as-plated, annealed plus plasma-nitrided samples. As mentions above increase CNTs concentration to $0.7 \mathrm{~g} / \mathrm{L}$ cause a significant raising in the roughness. In which CNT prevent uniform growth of Ni plus create of roughness. The sample roughness of Ni-B-0.7g/l CNT was higher when comparison with other specimens, because large concentration of CNT which may product agglomeration. Plasma-nitrided increased to roughness of the surface $(\mathrm{Ra})$ of the coatings. Since sputtering and re deposition occur during CPN process, surface roughness of the CPN coating is more than the annealed one. An increase in the surface roughness by plasma nitriding was also observed in the previous studies $[35,36]$.

There are three probable explanations for this product. First, follow to the process of Plasma-nitrided, growth of the crystal of $\mathrm{BN}$ and $\mathrm{Ni}_{2} \mathrm{~B}, \mathrm{Ni}_{3} \mathrm{~B}$ phases at the $\mathrm{Ni}$ matrix create of roughness and source the increased surface roughness .Second, the influence of sputtering through the procedure of Plasma-nitrided, affected by the positive hydrogen and nitrogen ion bombardment, caused on the samples roughness. Third, these result may be because re deposition of sputtering of material on the surface.

\section{Micro Hardness}

Figure 8 shows the surface of samples micro hardness of heat treatment and the plasma-nitrided. As noted, the CNTs reinforcing ability have force in enhancing the micro hardness of surface, particularly in the sample of (Ni-B-0.35g/l 
CNT).these can be related wither inforcement and uniform distribution of carbon nanotubes about these specimen. The hardness of (Ni-B-0.7g/l CNT) was less when comparison with the specimen that having $(0.35 \mathrm{~g} / \mathrm{L} \mathrm{CNT})$ due to the large CNTs concentration, in addition to that, segregation that happened at the composite led to a decrease in the composite microhardness of coated layer [37].

Increment in the microhardness with heat treatment is mainly attributed to the transformation from an amorphous to crystalline structure $[38,39]$. Follow the procedure of plasma-nitridin increased in the microhardness value occurred, because a creation of $\mathrm{Ni}_{2} \mathrm{~B}, \mathrm{Ni}_{3} \mathrm{~B}$ and $\mathrm{BN}$ phases [40].

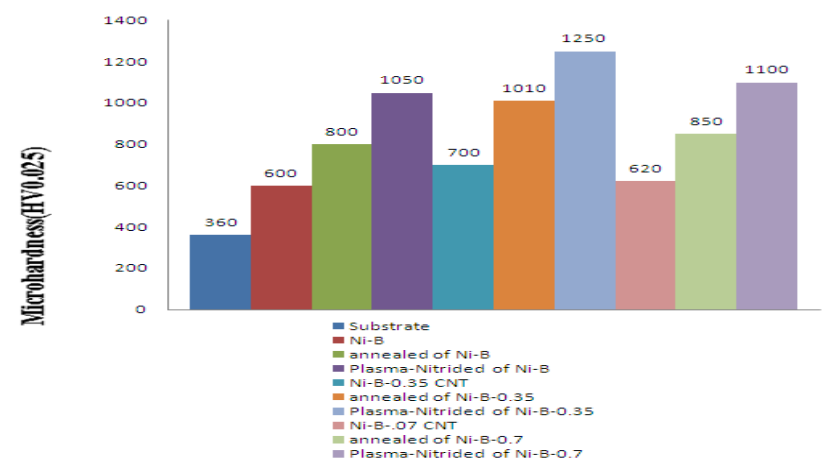

Figure 8: Micro Hardness Results of As-Plated and Plasma-Nitrided of Samples Surface.

\section{Corrosion Behaviour}

Table 5 include the results of test of electrochemical, $\mathrm{E}_{\text {corr., }} \mathrm{I}_{\text {corr. }}$ and corrosion rate coatings, evaluated by Tafel extrapolation technique in solution of $3.5 \% \mathrm{NaCl}$.

Potentiodynamic polarization curves measured on uncoated and NiB coated 4340 steel are shown on figure 9 . It is clear that the use of a Ni-B coating in enhancement of properties of the corrosion of AISI 4340 steel is due to thickness of electroless deposition is so uniform and the ability of Ni-B coatings to act as effective barrier between metal and corrosion media, the value of $E_{\text {corr }}$ is less negative, rate of the corrosion and $\mathrm{I}_{\text {corr }}$ is lesser on the plated sample than uncoated 4340steel are shown in table 5 [41].

However, the addition of CNT particle was really innovation. Samples which coated in the bath of different CNT concentrations, the samples were soaked in a solution of $3.5 \mathrm{wt} \% \mathrm{NaCl}$. Then curves of the polarization were evaluated. Figure (9) shows the effect of CNT on curve of polarization. Table (5) shows potential of the corrosion in different concentration of CNT. In the concentration of CNT of $0.35 \mathrm{~g} / \mathrm{L}$, the $\left(\mathrm{I}_{\text {corr }}\right.$ ) of Ni-B-CNTs composite coating is $(14.16 \mu \mathrm{A})$ $\mathrm{mV}$ and the $\left(\mathrm{I}_{\text {corr. }}\right)$ of Ni-B coating is $(27.83 \mu \mathrm{A})$ is due to the adding of CNT made the coating denser, with compared with coating of Ni-B , resistance of the corrosion of composite coating is better. With the increase of the CNT concentration of $0.7 \mathrm{~g} / \mathrm{L}$, leading to a high region of $\mathrm{CNT}$ agglomeration which is unfavorable to plating, potential of the corrosion for the composite coating becomes negative gradually, leading resistance of the corrosion of the composite coating becomes worse. It has been confirmed by other researchers $[42,43]$.

It achieves the best value when the CNT concentration was $0.35 \mathrm{~g} / \mathrm{L}$ CNT. Graphic observation of the curves after various treatments are shown in figure(9) indicates is less negative (Ecorr)values for heat treated and nitride specimens 
which show that those treatments improve the corrosion resistance of the Ni-Bwith Ni-B containing CNT samples a similar less negative Ecorr values trend was noticed after heat treatment and treatment of the plasma nitriding. The base causes for this behavior were the carbon nanotubes easily filled in the micro-holes of the surface through process of the electroless deposition. With increase in CNT concentration up to $0.35 \mathrm{~g} / \mathrm{L}$ lead to very less negative Ecorr values. The electrochemical behavior of plasm-nitrided coatings is even better than that of heat treated coatings, which is an effect of the chemical surface modification due to the nitrogen diffusion [44].

The formation and development of a dense and thick compound layer with nitriding at $400^{\circ} \mathrm{C}$ for $2.5 \mathrm{~h}$ corresponded for the high corrosion resistance of this sample due to formation of this layer assists passivation process and prohibits the penetration of $\mathrm{Cl}$-ions. in increase for concentration of the $\mathrm{CNT}$ of $0.7 \mathrm{~g} / \mathrm{L}$, potential of the corrosion of the composite plating becomes negative gradually, leading resistance of the corrosion of the composite plating becomes worse. This is because of with separation of the poor coherent agglomeration particles which nucleated and growth through agglomeration of CNT [45].

Table 5: The Results of Test of Electrochemical

\begin{tabular}{|l|c|c|c|}
\hline \multicolumn{1}{|c|}{ Sample } & $\mathbf{E}_{\text {corr. }}(\mathbf{m V})$ & $\mathbf{I}_{\text {corr. }}(\boldsymbol{\mu A})$ & Corrosion Rate(mpy) \\
\hline Substrate & -571 & 49.49 & 6.9 \\
\hline Ni-B as-a plated & -551 & 27.83 & 4 \\
\hline Ni-B-0.35g/LCNT as-a plated & -550 & 14.16 & 2 \\
\hline Ni-B-0.7g/L CNT as-a plated & -468 & 20.93 & 3 \\
\hline Ni-B as-annealed & -606 & 13 & 1.4 \\
\hline Ni-B-0.35g/L CNTas-annealed & -470 & 10.5 & 1.1 \\
\hline Ni-B-0.7g/L CNTas- annealed & -343 & 12.5 & 1.3 \\
\hline Ni-B as-a plasma-nitrided & -391 & 9 & 1 \\
\hline Ni-B-0.35g/L CNTas-a plasma-nitrided & -206 & 0.2 & 0.02 \\
\hline Ni-B-0.7g/L CNTas-a plasma-nitrided & -615 & 8.26 & 0.9 \\
\hline
\end{tabular}
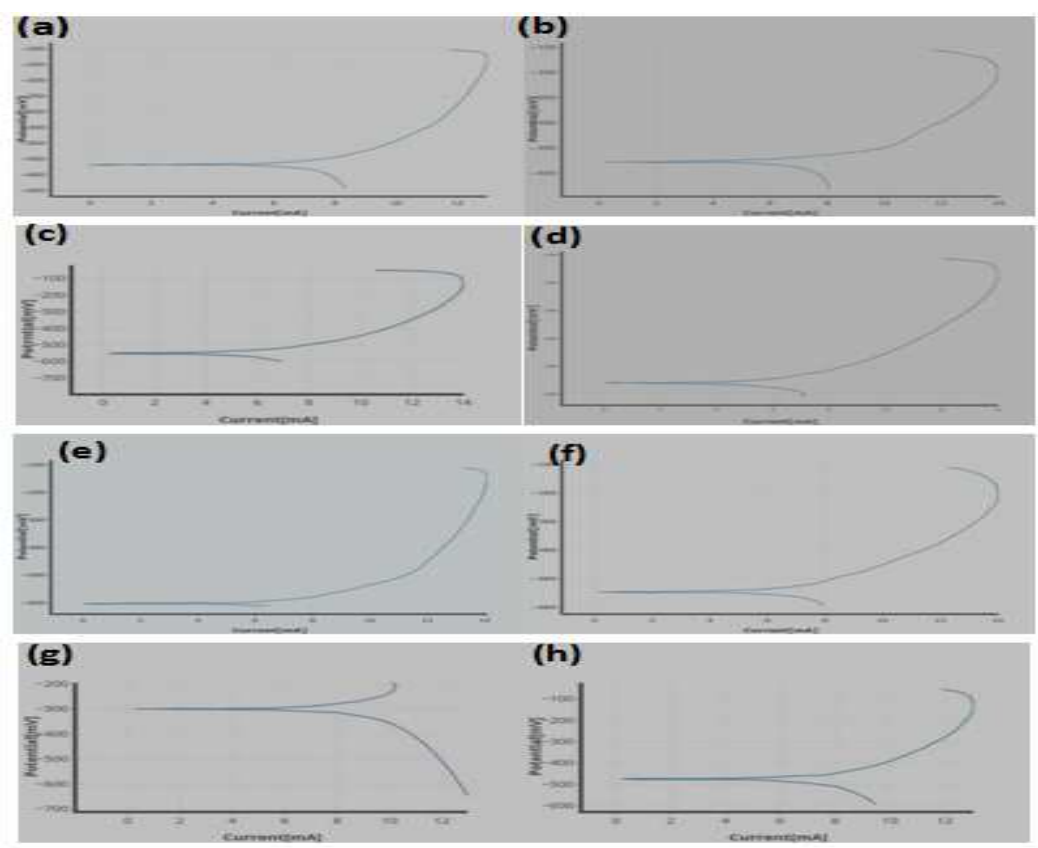

Figure 9: Polarization of Tafel Curves of The (A) As-Substrate , (B)Ni-B, (C) Ni-B-0.35 G/L CNT, (D) Ni-B-0.7 G/L CNT As-Plated, (E) Ni-B,(F) Ni-B-0.35g/L CNT, (G) Ni-B0.7g/L CNT As-Annealed and (H) Ni-B, (I) Ni-B-0.35 G/L CNT, (J) Ni-B-0.7g/L CNT Plasma-Nitrided Samples. 


\section{CONCLUSIONS}

Now a day, the characters of plasma nitriding of electroless (Ni-B) and (Ni-B-CNT) coating compare with those of annealed one. Under the experimental conditions, coatings of plasma-nitrided of electroless (Ni-B-CNT) result in the formation of BN and Ni2B, Ni3B phases, which increased micro hardness of the coatings. Although, the surface roughness increased, but mass loss in plasma nitride coatings decreased to the half of that in the annealed coating due to the higher micro hardness and smoother transition from the case to the core. In conclusion, plasma-nitriding process could be a suitable replacement for annealing procedure to produce more wear resistant electroless coatings investigation. From results that effect of carbon nanotubes experimental on structure of crystallographic of Ni-B electroless during easier of the nucleation of Ni. Increment concentration of CNT source on verted from amorphous structure to structure of crystalline. Distribution homogenously of CNT was transformed the morphology of surface coat with filling the crevices and cracks that formed through reaction of the hydrogen evolution. Particle growth and CNT inhibit crystal produce during creation of small nodules but for the sample of (Ni-B-0.7g/L CNT) in which happen the agglomeration because of a large concentration of CNT and so achieve a value higher of surface roughness. When concentration increase of CNT in as-plated samples lead to fall of both specific wear rate and friction coefficient which mainly result from the mechanism of self-lubricate of CNT. Whilst for the (Ni-B-0.7g/L CNT), because of their agglomeration and distribution of non-uniform of CNT, produce of increase in coefficient value of the friction. In other hand; plasma-nitrided of (Ni-B-CNT) and (Ni-B) electroless coating, produce interstitial diffusion of atoms of nitrogen in matrix of $\mathrm{Ni}$ and creation of $\mathrm{Ni2B}, \mathrm{Ni} 3 \mathrm{~B}$, and $\mathrm{BN}$ phases, consequently, increased the hardness. The present of CNT decrement of plastic deformation at the samples of plasma nitriding, as prevented generation of the excessive heat through test of the wear and resistance of the wear was enhanced. The larger resistance of wear related with the sample of (Ni-B-0.35g/l CNT). These can be associated with the smaller size of grain, larger micro hardness with distribution of uniform of the CNT. Other work on study the corrosion resistance properties will be a part of interest.

\section{REFERENCES}

1. R. Boccaccini and I. Zhitomirsky, Mater. Sci., 6 (2002) 251.

2. D. Thiemig and A. Bund, Surf. Coat. Tech., 202 (2008) 2976.

3. Z. Liu and W. Gao, Surf. Coat. Tech., 200 (2006) 5087.

4. L. p. Wu, J. j. Zhao, Y. p. Xie and Z.d. Yang, Trans. of Nonferrous Met. Soc. China., 2(2010) s630.

5. Riedel A. Electroless nickel plating. Finishing Publication LTD., London, 1989.US Patent 2.461.661, 1945.

6. P. Sahoo and S. K. Das, Mater. Design, 32 (2011) 1760.

7. Y. Yang, W. Chen, C. Zhou, H. Xu and W. Gao, App. Nanosci., 1 (2011) 19.

8. S. Afroukhteh, C. Dehghanian and M. Emamy, Mater. Inter., 22 2012) 480.

9. C. Li, Y. Wang and Z. Pan, Mater. Design, 47(2013) 443.

10. V. Vitry, A. Sens, A. F. Kanta and F. Delaunois, App. Surf. Sci., 263 (2012) 640.

11. Y. W. Riddle and T. O. Bailerare, J. Mater Proc. Tech., 57 (2005) 40.

12. T. S. N. Sankara Narayanan, A. Stephan and S. Guruskanthan, Surf. Coat. Tech, 179 (2004) 56.

13. K. Krishnaveni, T. S. N. Sankara Narayanan and S. K. Seshadri, Surf. Coat.Tech, 190 (2005) 115. 
14. Z. C. Wang, F. Jia, L. Yu, Z. B. Qi, Y. Tang and G. L. Song, Surf. Coat. Tech., 206, (2012) 3676.

15. F. Bülbül, H. Altun, V. Ezirmik and Ö. Küçük, J. Eng. Tribology., (2012) 1-11.

16. T. p. Xuan, L. Zhang and Q. h. Huang, Trans. Nonfer. Met. Soc. China., 16 (2006) 363.

17. H. B. Hassan, Z. A. Hamid, Int. J. Hydrogen Energy., 36 (2011) 849.

18. V. Vitry, A.-F. Kanta, F. Delaunois, Application of nitriding to electroless nickel-boron coatings: chemical and structural effects; mechanical characterization; corrosion resistance, Mater. Des. 39 (2012) 269-278.

19. Y. He, S. Wang, F. Walsh, Y.-L. Chiu, P. Reed, Self-lubricating Ni-P-MoS2 composite coatings, Surf. Coat. Technol. 307 (2016) 926-934.

20. Y. Wan, Y. Yu, L. Cao, M. Zhang, J. Gao, C. Qi, Corrosion and tribological performance of PTFE-coated electroless nickel boron coatings, Surf. Coat. Technol. 307 (2016) 316-323.

21. C. Carpenter, P. Shipway, Y. Zhu, Electrodeposition of nickel-carbon nanotube nanocomposite coatings for enhanced wear resistance, Wear 271 (2011) 2100-2105.

22. M.-F. Yu, O. Lourie, M.J. Dyer, K. Moloni, T.F. Kelly, R.S. Ruoff, Strength and breaking mechanism of multiwalled carbon nanotubes under tensile load, Science 287 (2000) 637-640.

23. P.C. Tsai, Y.R. Jeng, J.T. Lee, I. Stachiv, P. Sittner, Effects of carbon nanotube reinforcement and grain size refinement mechanical properties and wear behaviors of carbon nanotube/copper composites, Diam. Relat. Mater. 74 (2017) 197-204.

24. L. Melk, J.J.R. Rovira, M.-L. Antti, M. Anglada, Coefficient of friction and wear resistance of zirconia-MWCNTs composites, Ceram. Int. 41 (2015) 459-468.

25. Q. Wang, M. Callisti, A. Miranda, B. McKay, I. Deligkiozi, T. K. Milickovic, A. Zoikis- Karathanasis, K. Hrissagis, L. Magagnin, T. Polcar, Evolution of structural, mechanical and tribological properties of Ni-P/MWCNT coatings as a function of annealing temperature, Surf. Coat. Technol. 302 (2016) 195-201.

26. K. Zangeneh-Madar, S. M. MonirVaghefi: Surf. Coat. Technol., 2004, 182, 65-71.

27. Q.-L. Rao, G. Bi, Q.-H. Lu, H.-W. Wang, X.-L. Fan, Microstructure evolution of electroless Ni-B film during its depositing process, Appl. Surf. Sci. 240 (2005) 28-33.

28. E. Georgiza, V. Gouda, P. Vassiliou, Production and properties of composite electroless Ni-B-SiC coatings, Surf. Coat. Technol. 325 (2017) 46-51.

29. V. Vitry, A.-F. Kanta, F. Delaunois, Application of nitriding to electroless nickel-boron coatings: chemical and structural effects; mechanical characterization; corrosion resistance, Mater. Des. 39 (2012) 269-278.

30. V. Vitry, L. Bonin, Formation and characterization of multilayers borohydride and hypophosphite reduced electroless nickel deposits, Electrochim. Acta 243 (2017) 7-17.

31. A. Mukhopadhyay, T.K. Barman, P. Sahoo, Tribological behavior of sodium bor- ohydride reduced electroless nickel alloy coatings at room and elevated temperatures, Surf. Coat. Technol. 321 (2017) 464-476.

32. S. K. Das, P. Sahoo: Tribology in industry., 2010, 32, 17-25.

33. M. Anik, E. Korpe, E. §en, Effect of coating bath composition on the properties of electroless nickel-boron films, Surf. Coat. Technol. 202 (2008) 1718-1727.

34. M. HeydarzadehSohi, M. Ebrahimi, A. HonarbakhshRaouf, F. Mahboubi: Surf.Coat. Technol., 2010, 205, S84-S89. 
35. G. Prasad Singh, J. Alphonsa, P.K. Barhai, P.A. Rayjada, P.M. Raole, S. ukherjee: Surf. Coat. Technol., 2006, 200, $5807-5811$.

36. J. Umeda, B. Fugetsu, E. Nishida, H. Miyaji, K. Kondoh, Friction behavior of network-structured CNT coating on pure titanium plate, Appl. Surf. Sci. 357 (2015) 721-727

37. M. Yan, H. G. Ying, T. Y. Ma: Surf. Coat. Technol., 2008, 202, 5909-5913.

38. A. F. Kanta, V. Vitry, F. Delaunois: Mater. Lett., 2009, 63, 2662-2665.

39. V. Vitry, A.-F. Kanta, F. Delaunois, Mechanical and wear characterization of electroless nickel-boron coatings, Surf. Coat. Technol. 206 (2011) 1879-1885.

40. Y.L. Shi, Z. Yang, H. Xu, M.K. Li, H.L. Li, J. Mater. Sci., 39 (2004) 5809.

41. Kanta AF, Poelman M, Vitry V, Delaunois F. Nickel-boron electrochemical properties investigations. J Alloy Compd 2010; $505(1): 151-6$.

42. M. Alishahi, S. M. Monirvaghefi, A. Saatchi and S. M. Hosseini, Appl. Surf. Sci., 258 (2012) 2439.

43. Kanta AF, Vitry V, Delaunois F. Effect of thermochemical and heat treatments electroless nickel-boron. Mater Lett 2009; $63(30): 2662-5$.

44. Li Y, Wang L, Shen L, Zhang D, Wang C (2010) Plasma nitriding of 42CrMo low alloy steelsat anodic or cathodic potentials. Surf Coat Technol 204:2337-2342

\section{AUTHORS PROFILE}

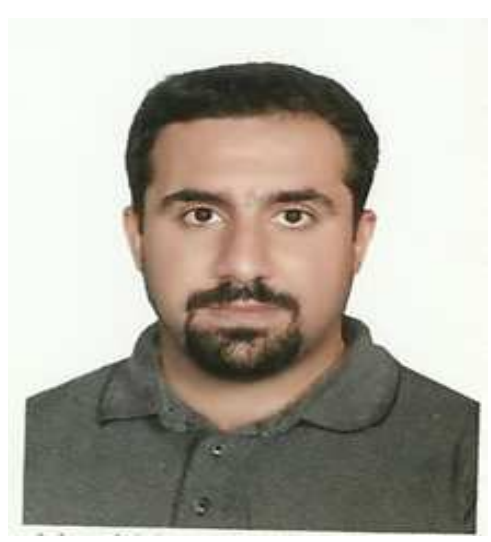

(Alaa Mohammed Hussein Wais) born in Hilla 1979 and received BSC in material engineering in Babylon university in 2002. I complete M.Sc.in material engineering in the field of Effect Of Friction Stir Processing On Mechanical Properties of The Cast Aluminum-Silicon Alloysin 2013. I studies Tribological behaviour of plasma nitride nano composite coating of Ni-B-Carbon nanotubes in PhD project in 2019 (Date of discussion PhD project). I had more 8 papers. Now more attention in the surface engineering field to enhance surface properties against wear and corrosion effects. I am studying in Al-Mustaqbal University College, Babylon, Iraq since 2014 


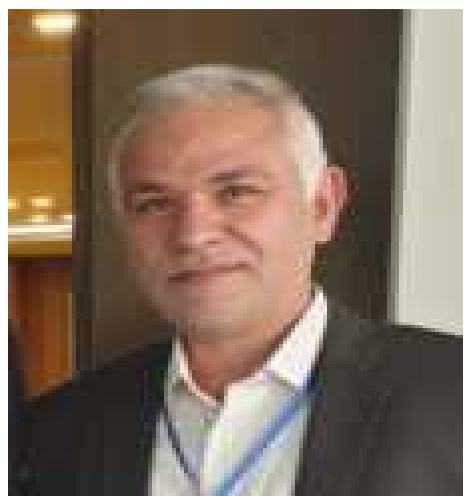

(Abdul Raheem K. AbidAli) born in Hilla 1975 and received BSC in material engineering in Babylon university in 1997. I complete M.Sc.in material engineering in the field of stress analysis of laminated composite by finite element analysis in 2000. I studies the martensitic transformation and mechanical behavior of copper based shape memory alloy in $\mathrm{PhD}$ project in 2007. I had more 45 papers since 2008 in the Ni Ti shape memory alloy and in the field composite of material. Now more attention in the surface engineering field to enhance surface properties against wear and corrosion effects.

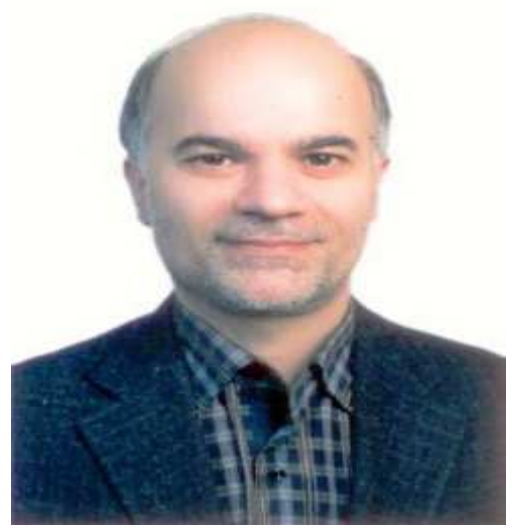

(Farzad Mahboubi). Ph.D. Materials Engineering, University of Wollongong, Australia 1995. M.Sc. (HONS). Materials Engineering, University of Wollongong, Australia 1991. B.Sc. Materials Engineering, Sharif University of Technology, Iran 1988, Employment and Teaching (July 1995-2006, Assistant Professor, 2006, 2016 Associate Professor, 2016Amirkabir university of technology) Professor, Administration Jobs (Sep. 1995-present, Director of Heat Treatment Laboratory, April 1997-2005, Director of Scanning Electron Microscope Laboratory, Oct. 1996-July 2000, Head of Materials Engineering Group, July 2000-Nov. 2002, Deputy Head of Department for Educational Affairs, August 2006 to 2008, Deputy Head of Department for Administration and Finance Affairs, February 2009 to February 2011, General Manager of Technology and Industrial Relations of the University, February 2011 to 2015, Head of Petroleum Engineering Department 